\title{
MJN \\ LOW BACK PAIN AMONG REGISTERED NURSES IN SURGICAL UNIT AT RAJA PEREMPUAN ZAINAB (RPZ) II HOSPITAL, KOTA BHARU, KELANTAN
}

\author{
Norhaizan Jann, Chan Siok Gim* \\ Open University Malaysia, Kota Bharu, Kelantan \\ *Corresponding Author's Email: siokgimchan@yahoo.com
}

\begin{abstract}
Low back pain is a common occupational health issue especially among nurses that leads to suffering, disability and days of work lost that affect the continuity and quality of patients care. This study aims to determine prevalence of low back pain among registered nurse at Surgical Unit in RPZ II Hospital and identify the associated factors. It is a cross-sectional study that used a self-administered questionnaire to collect the data among a convenience sample of 60 nurses.

Data was analyzed using Pearson Chi-Square. Majority of them were aged 31 to 40 years (53.3\%), Malays $(91.5 \%)$, married $(84.6 \%)$, had working experience from 11 to 15 years $(50.8 \%)$, had formal manual handling training $(64.9 \%)$ and are overweight $(58.3 \%)$. The prevalence of low back pain was $63.8 \%$. The study revealed statistical significance for race $(p=0.002)$, number of patients they have to handle $(p=0.005)$, satisfaction with working environment $(p=0.007)$ and emotional and social problems $(p=0.007$, $p=0.038$, respectively).
\end{abstract}

Keywords: Low Back Pain, Nursing, Low Back Pain, Emotional and Social Problems

\section{INTRODUCTION}

Low back pain has become increasingly common worldwide. Low back pain has been ranked as one of the leading causes of disability out of the 291 conditions studied (Hoy et al., 2014). The prevalence of low back pain was estimated to be about 31 percent among the general adult population globally. As low back pain becomes the primary concern for employment disability, the National Institute of Neurological Disorders (NINDS) states that the cause is due to sedentary lifestyles and behaviors, both at home and in the workplace. Low back pain is sometimes referred to generally as lumbago, a common symptom of musculoskeletal disorders or of disorders involving the umbar vertebrae. It can be either acute, sub acute or chronic in its clinical presentation. Typically, the symptoms of low back pain do show significant improvement within two to three months from its onset.
In a significant number of individuals, low back pain tends to be recurrent in nature with a waxing and waning quality to it. In a small proportion of sufferers this condition can become chronic. Population studies show that back pain affects most adults at some stage in their life and accounts for more sick leave and disability than any other single medical condition (Freburger, 2009).

The aim of this study was to investigate whether the nurses in the Surgical Unit of RPZ II Hospital are having low back pain; and if any, to what extent. This study will also investigate the factors that result in low back problem among the registered nurses in RPZ II Hospital. Since there are not many literatures reporting on Malaysia nurses, the British and American literature will be used as a data resource.

There are many studies that had been conducted 
around the world related to this problem. In Brazil, Petersen \& Marziale (2014) did a study on low back pain and its contributing factors among nurses who work in intensive care unit. These nurses had high exposure to occupational risk that contributes to low back pain. There is an association between prevalence of low back pain and work characteristics (Kim et al., 2014). Besides that, several high risk activities have been identified for nurses in the hospital especially in relation to low back pain, for example the most important factor related to work load is rapid movement combined with poor body posture especially when nurses perform their duties under time pressure (Hinmikaiye \& Bamishaiye, 2012).

This problem had also been experienced by nurses in Asia. In Thailand, even the policy of Hospital Accreditation (HA) partially focuses on improving the workplace environments of all certified hospitals, the low back pain prevalence still high (Sopajareeya et al., 2009). Castro et al., (2009). mentioned that approximately 40 percent of nurses in Philippines experienced illness and injury issues in the past year and 80 percent experienced low back pain. In Malaysia, this problem also had been highly focused as nurses are the backbone of the healthcare system. One study done in Sabah, Malaysia by Wong, Teo \& Kyaw, (2007) regarding prevalence of low back pain among healthcare workers found that nurses are the most affected by low back pain problem. The high prevalence among nurses can be explained by the heavy workloads and work conditions, particularly the requirement for heavy lifting.

As mentioned by Wong, Teo \& Kyaw, (2007) hospital workers especially nurses seem to have higher rates of low back pain compared to the general population. The direct and indirect cost of low back pain in terms of quality of life, productivity and employee absenteeism are enormous. There are many aggravating factors that result in low back pain among the nurses, besides work demand such as lifting which is considered as the most common factor. Low back pain in the nurses are also associated with other several factors, such as length of service, age, body weight, work area and level knowledge in manual handling and psychological factors.

\section{RESEARCH METHODOLOGY}

\section{Sample Profile}

A total 60 registered nurses at Surgical Department from wards 28, 29, 30 and Anggerik in Raja Perempuan Zainab (RPZ) II Hospital were involved in this study.
Table 1: Age Distribution

\begin{tabular}{|l|c|c|}
\hline Age (years) & $\begin{array}{c}\text { Frequencies } \\
\boldsymbol{n}\end{array}$ & $\begin{array}{c}\text { Percent } \\
(\mathbf{\%})\end{array}$ \\
\hline 30 and below & 24 & 40.0 \\
31 to 40 & 32 & 53.3 \\
41 to 50 & 4 & 6.7 \\
51 and above & 0 & 0 \\
\hline Total & 60 & 100.0 \\
\hline
\end{tabular}

Majority of the participants, 32 nurses involved in this study were aged between 31 to 40 years old. This is followed by 24 nurses aged 30 and below, and the minority group of four nurses were aged 41 to 50 years. None were aged 51 years and above ( table 1$)$.

\section{Table 2: Race Distribution}

\begin{tabular}{|l|c|c|}
\hline Race & $\begin{array}{c}\text { Frequencies } \\
\boldsymbol{n}\end{array}$ & $\begin{array}{c}\text { Percentage } \\
\mathbf{( \% )}\end{array}$ \\
\hline Malay & 54 & 91.5 \\
Chinese & 5 & 8.5 \\
India & 0 & 0 \\
Others & 0 & 0 \\
Missing data & 1 & 1.7 \\
\hline Total & 60 & 100.0 \\
\hline
\end{tabular}

The majority, $91.5 \%$ of the nurses was Malays and minority group was Chinese. One of them did not answer the question (table 2).

\section{Table 3: Marital Status Distribution}

\begin{tabular}{|l|c|c|}
\hline Marital status & $\begin{array}{c}\text { Frequencies } \\
\boldsymbol{n}\end{array}$ & $\begin{array}{c}\text { Percentage } \\
(\%)\end{array}$ \\
\hline Single & 7 & 11.9 \\
Married & 51 & 86.4 \\
Divorced & 1 & 1.7 \\
Missing Data & 1 & 1.7 \\
\hline Total & 60 & 100.0 \\
\hline
\end{tabular}

Majority of the participants, 51 nurses were married. Seven nurses were still single and only one was divorced. One participant did not answer the question (table 3).

Table 4: Academic Qualification Distribution

\begin{tabular}{|l|c|c|}
\hline Academic qualification & $\begin{array}{c}\text { Frequencies } \\
\boldsymbol{n}\end{array}$ & $\begin{array}{c}\text { Percentage } \\
\text { (\%) }\end{array}$ \\
\hline STPM & 3 & 5.0 \\
SPM/MCE & 7 & 11.7 \\
Diploma & 47 & 78.3 \\
Bachelor & 2 & 3.3 \\
Master & 0 & 0 \\
PhD & 0 & 0 \\
Missing data & 1 & 1.7 \\
\hline Total & 60 & 100.0 \\
\hline
\end{tabular}


Table 4 shows more than half of the participants, 47 nurses have diploma. Only two of them have Bachelor degree of nursing.

\section{Table 5: Working Experience Distribution}

\begin{tabular}{|l|c|c|}
\hline Working experience (years) & $\begin{array}{c}\text { Frequencies } \\
\boldsymbol{n}\end{array}$ & $\begin{array}{c}\text { Percentage } \\
\text { (\%) }\end{array}$ \\
\hline Five or less & 0 & 0 \\
Six to 10 & 0 & 0 \\
11 to 15 & 30 & 50.0 \\
16 to 20 & 11 & 18.3 \\
21 and more & 18 & 30.0 \\
Missing data & 1 & 1.7 \\
\hline Total & 60 & 100.0 \\
\hline
\end{tabular}

None of the participant had less than 10 years working experience. The most senior 18 nurses had about 21 years experience and more. Majority of them had only 11 to 15 years of working experience (table 5).

\section{Table 6: Training in Manual Handling}

\begin{tabular}{|l|c|c|}
\hline Formal training & $\begin{array}{c}\text { Frequencies } \\
\boldsymbol{n}\end{array}$ & $\begin{array}{c}\text { Percentage } \\
\mathbf{( \% )}\end{array}$ \\
\hline Yes & 37 & 61.7 \\
No & 20 & 33.3 \\
Missing data & 3 & 5.0 \\
\hline Total & 60 & 100.0 \\
\hline
\end{tabular}

A total of 37 nurses who are involved in this study attended formal training in manual handling, this represent about 61.7 percent of the participants. However there are about 3 nurses who have not answered the question (table 6).

\section{Table 7: BMI Classification}

\begin{tabular}{|l|c|c|}
\hline BMI & $\begin{array}{c}\text { Frequencies } \\
\text { classification }\end{array}$ & $\begin{array}{c}\text { Percentage } \\
\mathbf{( \% )}\end{array}$ \\
\hline Underweight & 2 & 3.3 \\
Normal & 23 & 38.3 \\
Overweight & 35 & 58.3 \\
\hline Total & 60 & 100.0 \\
\hline
\end{tabular}

Classification of the BMI was based on WHO (2004) for Asian country BMI classification. Majority of the nurses (35) were classified as overweight which was more and equal to $25 \mathrm{~kg} / \mathrm{m}$. However about two nurses were classified as underweight which was less than $18.5 \mathrm{~kg} / \mathrm{m}^{2}$ (table 7 ).

\section{Instrumentation}

Questionnaire used consists of two parts with closeended questions. Demographic Data in Section A where the items asked for all personal data which include age, height, and weight, length of service, marital status and level of knowledge in manual handling. Section B consists of items on Low Back Pain and Visual Analogue scale (VAS). In this section, subjects were asked whether they are having low back pain or not, if they have, they are required to rate their pain level by filling a numeric rating Visual Analogue Scale, VAS Subjects were asked to indicate on scale ranging from 0 to 10 , where 0 represents no pain while 10 represents the most severe pain.

\section{Data Collection Method}

The questionnaires were distributed to the nurses at the Surgical Department of Raja Perempuan Zainab (RPZ) II Hospital during January 2014 by the researcher. The questionnaire was self-administered. Before answering the questions they need to give their consent first. Then the subjects returned the questionnaire to the sister in charge.

\section{RESULTS}

\section{Table 8: Prevalence of Low Back Pain}

\begin{tabular}{|l|c|c|}
\hline $\begin{array}{l}\text { Pain/discomfort over low } \\
\text { back for past one year }\end{array}$ & $\begin{array}{c}\text { Frequencies } \\
\boldsymbol{n}\end{array}$ & $\begin{array}{c}\text { Percentage } \\
(\mathbf{\%})\end{array}$ \\
\hline Yes & 37 & 63.8 \\
No & 21 & 36.2 \\
Missing data & 2 & 3.3 \\
\hline Total & 60 & 100.0 \\
\hline
\end{tabular}

Among 60 participants, 37 nurses complaint of having low back pain (table 8). However most of them did not report the severity of the pain.

\section{Table 9: Ages and Low Back Pain}

\begin{tabular}{|l|c|c|c|}
\hline Age (years) & Yes & No & Total \\
\hline 30 and below & & & \\
31 to 40 & 15 & 9 & 24 \\
41 to 50 & 20 & 10 & 30 \\
51 and above & 2 & 2 & 4 \\
& - & - & - \\
\hline Total & 37 & 21 & 58 \\
\hline
\end{tabular}

*2 missing data

Pearson Chi-Square $=0.454, d f=2, p=0.797$

Among the registered nurses, 37 of them professed to have low back pain (table 9). However with increasing age the prevalence of low back pain decreased probably because the senior nurses were then given administrative posts. Pearson Chi-Square analysis showed there is no association between age and prevalence of low back pain. 
Table 10: Race and low back pain

\begin{tabular}{|l|c|c|c|}
\hline Race & Yes & No & Total \\
\hline Malay & 36 & 16 & 52 \\
Chinese & - & 5 & 5 \\
India & - & - & \\
Others & - & - & 57 \\
\hline Total & 36 & 21 & \\
\hline
\end{tabular}

*3 missing data

Pearson Chi-Square $=9.396, d f=1, p$-value $=0.002 *$

Majority of the registered nurses (52) were Malay, among them 36 nurses complaint of low back pain. Pearson Chi-Square analysis showed a significant association $p<0.05$ between race and the prevalence of low back pain due to the truncated sample used (table $10)$.

\section{Table 11: Marital Status and Low back pain}

\begin{tabular}{|l|c|c|c|}
\hline Marital status & Yes & No & Total \\
\hline Single & 4 & 3 & 7 \\
Married & 32 & 18 & 50 \\
Divorced & 1 & - & 1 \\
\hline Total & 37 & 21 & 58 \\
\hline
\end{tabular}

*2 missing data

Pearson Chi-Square Test $=0.703, d f=2, p$-value $=0.704$

Majority of the registered nurses, 50 nurses were married, 32 nurses complain of low back pain. However Pearson Chi-Square showed no significant association between marital status and prevalence of low back pain (table 11).

\section{Table 12: Academic Qualifications and Low back pain}

\begin{tabular}{|l|c|c|c|}
\hline Qualification & Yes & No & Total \\
\hline STPM & 2 & 1 & 3 \\
SPM/MCE & 6 & 1 & 7 \\
Diploma & 28 & & 46 \\
Bachelor & 1 & 1 & 2 \\
Master & - & - & - \\
PhD & - & - & - \\
\hline Total & 37 & 21 & 58 \\
\hline *2 missing data
\end{tabular}

Pearson Chi-Square Test $=1.802, d f=3, p$-value $=0.614$

Majority of the 46 registered nurses had diploma, out of them 28 nurses complained of low back pain. However Pearson Chi-Square showed no significant association between academic qualification and prevalence of low back pain (table 12).
Table 13: Working Experience and Low Back Pain

\begin{tabular}{|l|c|c|c|}
\hline Experience & Yes & No & Total \\
\hline Five or less & - & - & - \\
Six to 10 & - & - & - \\
11 to 15 & 20 & 9 & 29 \\
16 to 20 & 7 & 4 & 11 \\
21 and more & 10 & 8 & 18 \\
\hline Total & 37 & 21 & 58 \\
\hline *2 missing data
\end{tabular}

Pearson Chi-Square Test $=0.865, d f=2, p$-value $=0.649$

Majority of the registered nurses, 29 nurses had about 11 to 15 years working experience and most of them, (20 nurses) complained of low back pain (table 13). However Pearson Chi-Square showed no significant association between working experience and prevalence of low back pain.

Table 14: Formal Training in Manual Handling and Low back pain

\begin{tabular}{|l|c|c|c|}
\hline $\begin{array}{l}\text { Formal } \\
\text { Training }\end{array}$ & Yes & No & Total \\
\hline Yes & 22 & 15 & 37 \\
No & 13 & 6 & 19 \\
\hline Total & 35 & 21 & 56 \\
\hline
\end{tabular}

*4 missing data

Pearson Chi-Square Test $=0.430, d f=1, p$-value $=0.512$

Majority of the registered nurses had formal training in manual handling, 37 nurses. Still, most of them complain low back pain, 22 nurses. Pearson ChiSquare showed no association between working experienced and prevalence of low back pain.

\section{Table 15: BMI Classifications and Low back pain}

\begin{tabular}{|l|c|c|c|}
\hline BMI & Yes & No & Total \\
\hline Underweight & 1 & 1 & 2 \\
Normal & 12 & 11 & 23 \\
Overweight & 24 & 9 & 33 \\
\hline Total & 37 & 21 & 58 \\
\hline
\end{tabular}

*2 missing data

Pearson Chi-Square Test $=2.649, d f=2, p$-value $=0.266$

Majority of the registered nurses, 33 of them were classified as overweight. Prevalence of low back pain was higher among overweight nurses (table 15). However, Pearson Chi-Square showed no association between BMI classification and prevalence of low back pain. 
Table 16: Number of Patients Handled and Low Back Pain

\begin{tabular}{|l|c|c|c|}
\hline Number of patients & Yes & No & Total \\
\hline Zero to Three & 7 & 13 & 20 \\
Four to Six & 15 & 5 & 20 \\
Seven to Nine & 14 & 3 & 17 \\
more to 10 & - & - & - \\
\hline Total & 36 & 21 & 57 \\
\hline
\end{tabular}

*3missing data

Pearson Chi-Square Test $=10.712, d f=2, p$-value $=0.005^{*}$

Majority of the registered nurses during their working hour needs to lift or transfer patients from one bed to the other for about 5 to 6 times a day. A total of 20 nurses stated that they handled about zero to three patients, and 20 nurses claimed to have handled about four to six patients. Most of the nurses complained of low back pain (table 16). Prevalence of low back pain increases when number of patients that are to be handled increase. Pearson Chi-Square showed a significant association between the numbers of patients lifted or transferred to one bed from the other and low back pain.

\section{Table 17: Working Environment Satisfaction and} Low Back Pain

\begin{tabular}{|c|c|c|c|}
\hline Satisfaction & Yes & No & Total \\
\hline Yes & 14 & 16 & 30 \\
No & 22 & 5 & 27 \\
\hline Total & 36 & 21 & 57 \\
\hline
\end{tabular}

*3 missing data

Pearson Chi-Square Test $=7.402, d f=1, p$-value $=0.007^{*}$

Majority of the registered nurses (30) stated that they were satisfied with the working environment. Prevalence of low back pain increases when they are not satisfied with the working environment. Pearson Chi-Square showed a significant association between working environment satisfaction and prevalence of low back pain (table 17).

\section{Table 18: Emotional Problems and low back pain}

\begin{tabular}{|l|c|c|c|}
\hline Emotional Problem & Yes & No & Total \\
\hline Not at all & 8 & 11 & 19 \\
Slightly & 13 & 9 & 22 \\
Moderately & 13 & 1 & 14 \\
Severe & 2 & - & 2 \\
Very severe & - & - & - \\
\hline Total & 36 & 21 & 57 \\
\hline
\end{tabular}

*3 missing data

Pearson Chi-Square Test $=10.249, d f=3, p$-value $=0.017^{*}$
In Table 18, 22 of the registered nurses stated that they only had slight problem with work/regular activities due to emotional problem over the past one year. Prevalence of low back pain increases when they have moderate problem with work or regular activities. Pearson Chi-Square showed a significant association between problems associated with work or regular activities due to emotional problem over the past one year and prevalence of low back pain have also been observed.

\section{Table 19: Social Problems and Low back pain}

\begin{tabular}{|l|c|c|c|}
\hline Social Problems & Yes & No & Total \\
\hline Not at all & 8 & 11 & 19 \\
Slightly & 16 & 9 & 25 \\
Moderately & 10 & 1 & 11 \\
Severe & 2 & - & 2 \\
Very severe & - & - & - \\
\hline Total & 36 & 21 & 57 \\
\hline
\end{tabular}

*3 missing data

Pearson Chi-Square Test $=8.434, d f=3, p$-value $=0.038^{*}$

About 25 registered nurses stated that they are only slightly affected by social problems related to family, neighbors or groups over the past one year (table 19). Prevalence of low back pain increase when they had slightly problem with work or regular activities. Pearson Chi-Square showed a significant association between problem with work or regular activities due to emotional problem over the past one year and prevalence of low back pain.

\section{DISCUSSION}

This study found that there was a highly significant association between race and prevalence of low back pain. In study done by Wong, Teo \& Kyaw (2010), also found a significant association between these variables. Study done in United States had reported about a significant difference between black and Latino populations (Hollingshead et al., 2016). Increased number of patients lifted or transferred to bed or from bed during working hour of the registered nurses was associated with higher prevalence of low back pain. This finding was already proven by previous studies. Nurses who handled patients frequently were three times more likely to have low back pain compared to infrequent patient handlers (Jensen, 1990). French et al., (1997) also mentioned that two major contributing factors of prevalence of back pain nurses were lifting 
and transferring patients.

However in one study done among female health care worker in elder care services in Denmark, an association between number of patients handled was compared to non-handlers (Elders \& Burdorf, 2001). Satisfactions' with working environment was a significant factor that associated with prevalence of low back pain in this study. Previous studies had also found significant association (Hoogendoorn et al., 2002). The researchers mentioned that low back pain could be reduced by improving their satisfaction with the working environment. Study done by Eriksen, Bruusgaard \& Knardahl (2004), among nurses aid also found that perceived lack of pleasant and relaxing culture in the work unit were the main factors that contribute to high complaint of low back pain.

This study found a significant association between emotional problem and low back pain. Nurses who do not enjoy their work complaint of having low back pain almost twice as often as nurses who enjoyed their work (Yip, 2001). WebMD (2011) suggested stress and low back pain form a vicious circle. When they had back pain, they begin to worry about it. This in turn causes stresss and their back muscles begin to tense. Tense muscles make back pain worse and they worry more.

Besides that, Erikson et al., (2004) also mentioned that lack of familial support and social work support was associated with prevalence of low back pain. This study also found a significant association between problems with social activities with family, neighbors' or groups due to depressed/anxious over past one year and prevalence of low back pain.

\section{CONCLUSION}

Using Pearson Chi-Square analysis we are able to find the factors that are associated with the prevalence of low back pain among nurses in surgical unit of RPZ II Hospital. The present study has found many factors that can aggravate the problem. Although there are some limitations in this study, we only can find five significant factors that cause low back pain among nurses. They are Race, Number of patients handled, and Satisfaction with working environment, Emotional and Social problems.

\section{REFERENCES}

Castro, A. B. D., Cabrera, S. L., Gee, G. C., Fujishiro, K. \& Tagalog, E. A. (2009). Occupational Health and Safety Issues among Nurses in the Philippines. American Association of Occupational Health Nurse Journal, 57(4), pp 149-157.

Elders, L. A \& Burdorf, A. (2001). Interrelations of risk factors and low back pain in scaffolders. Occupational and Environmental Medicine, 58(9), pp 597-603.

Eriksen, W., Bruusgaard, D. \& Knardahl, S. (2004). Work factors as predictors of intense or disabling low back pain; a prospective study of nurses' aides. Occupational and Environmental Medicine, 61(5), pp 398-404.

French, P., Flora, L.F.W., Ping, L.S \& Rita, W.H.Y. (1997). The prevalence and cause of occupational back pain in Hong Kong registered nurses. Journal of Advanced Nursing. 26 (2), pp 380-388.

Freburger, J. K., Holmes, G. M., Agans, R. P., Jackman, A. M., Darter, J. D., Wallace, A. S., Castel, L.D., Kalsbeek, W. D \& Carey, T. S.(2009). The Rising Prevalence of Chronic Low Back Pain. Archives of Internal Medicine, 169(3), pp 251-258.

Hollingshead, N.A., Ashburn-Nardo, L., Stewart, J.C.\& Hirsh, A.T, (2016).The pain experience of Hispanic Americans: A critical literature review and conceptual model. Journal of Pain, 17(5), pp 513-528.

Hinmikaiye, C. D. \& Bamishaiye, E. I. (2012). The incidence of low back pain among theatre nurses: A case study of University of Ilorin and Obafemi Awolowo University Teaching Hospital. International Journal of Nursing Science, 2(3), pp 23-28. 
Hoogendoorn, W. E., Bongers, P. M., de Vet, H. C. W., Ariëns, G. A., van Mechelen, W. \& Bouter, L. M. (2002). High physical work load and low job satisfaction increase the risk of sickness absence due to low back pain: results of a prospective cohort study. Occupational and environmental medicine, 59(5), pp 323-328

Hoy, D., March, L., Brooks, P., Blyth, F., Woolf, A., Bain, C., Williams, G., Smith, E., Vos, T., Barendregt. J., Murray, C., Burstein, R. \& Buchbinder, R. (2014). The global burden of low back pain: estimates from the Global Burden of Disease 2010 study. Annals of Rheumatic Diseases, 73(6), pp 968-974.

Jensen, R.C. (1990). Back injuries among nursing personnel related to exposure. Applied Occupational and Environmental Hygiene, 5, pp 38-45.

Kim, S.S., Okechukwu, C.A., Dennerlein, J.T., Boden, L.I., Hopcia, K., Hashimoto, D.M. \& Sorensen, G. (2014).Association between perceived inadequate staffing and musculoskeletal pain among hospital patient care workers. International Archives of Occupational and Environmental Health, 87(3), pp 323-330.

Petersen, R. D. S. \& Marziale, M. H. P. (2014).Low back pain characterized by muscle resistance and occupational factors associated with nursing. Revista Latino-Americana de Enfermagem, 22(3), pp 386-393.

Sopajareeya, C., Viwatwongkasem, C., Lapvongwatana, P., Hong, O. \& Kalampakorn, S. (2009). Prevalence and risk factors of low back pain among nurses in a Thai public hospital. Journal of the Medical Association of Thailand, 92(7), pp S93-S99.

WebMD. (2011). Stress Relaxation and Natural Pain Relief. Retrieved from : http://www.webmd.com/backpain/reduce-life-stress-to-relieve-low-back-pain

Wong, T.S., Teo, N. \& Kyaw, M.O. (2010). Prevalence and Risk Factors Associated with Low Back Pain among Health Care Providers in a District Hospital. Malaysian Orthopedics Journal, 4(2) pp 23 -28.

World Health Organization (2004) Appropriate body-mass index for Asian populations and its implications for policy and intervention strategies. The Lancet, 363, pp 157-163.

Yip, Y. (2001). A study of work stress, patient handling activities and the risk of low back pain among nurses in Hong Kong. Journal of Advanced Nursing, 36(6),pp 794-804. 